I N S T I T U T O

$\mathrm{DE}$

M E D I C I N A

T R O P I C A L

DE

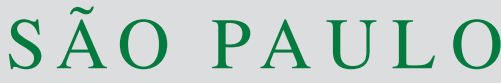

JOURNAL OF THE SÃO PAULO INSTITUTE OF TROPICAL MEDICINE

In memory of Cristina Adelaide Figueiredo

${ }^{1}$ Instituto Adolfo Lutz, Centro de Virologia, Núcleo de Doenças Respiratórias, São

Paulo, São Paulo, Brazil

2Instituto Adolfo Lutz, Núcleo de Microscopia Eletrônica, São Paulo, São Paulo, Brazil

${ }^{3}$ Instituto Adolfo Lutz, Centro de Virologia, Núcleo de Doenças de Vinculação Sexual e Sanguínea, São Paulo, São Paulo, Brazil

Correspondence to: Maria Isabel de Oliveira

Instituto Adolfo Lutz, Centro de Virologia, Núcleo de Doenças Respiratórias, Av. Dr. Arnaldo, 355, CEP 01246-902, São Paulo, SP, Brazil

Tel: +55 1130682906

Fax: +55 1130883753

E-mail: olive40@uol.com.br

Received: 1 September 2017

Accepted: 7 February 2018
http://dx.doi.org/10.1590/S1678-9946201860015

\section{Isolation of infectious Zika virus from a urine sample cultured in SIRC cells from a patient suspected of having rubella virus}

\author{
Maria Isabel de Oliveira1', Gislene Mitsue Namiyama², Gabriela Bastos \\ Cabral $^{3}$, João Leandro Ferreira ${ }^{3}$, Noemi Taniwaki ${ }^{2}$, Ana Maria Sardinha \\ Afonso', Isabella Rillo Lima', Luís Fernando Macedo de Brigido ${ }^{3}$
}

\section{ABSTRACT}

A great variety of viruses which cause exanthema share other clinical manifestations, making the etiologic identification a very difficult task, relying exclusively on the clinical examination. Rubella virus (RV) infection during the early stages of pregnancy can lead to serious birth defects, known as congenital rubella syndrome (CRS). In the present report, we described the presence of Zika virus (ZIKV) particles in urine samples and also ZIKV isolation in SIRC cells from the urine of a patient in acute phase of suspected rubella disease. The 50-year-old unvaccinated woman living in Sao Paulo, Brazil, was admitted to the emergency room with fever, headache, rash, arthralgia and prostration. Urine samples were collected for virus isolation and RT-qPCR. SIRC and Vero cells were inoculated with urine samples during 7 days. RT-qPCR was performed using measles virus (MV) and RV primers and both were found to be negative. After this result, RT-qPCR was performed for parvovirus B19, herpes virus 6 and ZIKV. The urine sample and the isolate were positive by Real Time PCR for ZIKV and negative for all other viruses tested. The sequences isolated are from the Asiatic lineage.

KEYWORDS: Zika virus. Rubella virus. Isolation. Genotype.

\section{INTRODUCTION}

Rubella virus infection is characterized by a maculopapular rash and cervical, suboccipital or postauricular adenopathy or arthralgia/arthritis ${ }^{1}$. Up to $50 \%$ of infections are asymptomatic or subclinical and symptoms are similar to those caused by measles virus and other etiologies associated with rash, so that the clinical diagnosis of rubella is unreliable $e^{2,3}$.

Moreover, a great variety of viruses which cause exanthema, share other clinical manifestations, making the etiologic identification a very difficult task, relying exclusively on the clinical examination. The most common agents include the measles virus, rubella, dengue, varicella, cytomegalovirus, Epstein Barr, enteroviruses, human parvovirus B19 and type 6 human Herpes virus, 7 (HHV-7) and HIV. Recently, Chikungunya and Zika virus (ZIKV) ${ }^{4-6}$ have expanded the list. In this report, we describe the presence and isolation in SIRC cells of Zika virus particles from the urine of a patient in the acute phase of a suspected rubella disease. This is the first report of Zika virus isolation and growth in SIRC cells. 


\section{CASE REPORT}

A 50-year-old woman, living in Sao Paulo, Brazil, was admitted to the emergency room with a 2-day history of fever $\left(38^{\circ} \mathrm{C}\right)$, headache, rash, arthralgia and prostration. As she was not vaccinated against rubella/measles virus (RV/MV), serum immunoglobulin IgM and IgG antibodies raised to these viruses and were found to be negative (Abbott AxSYM Rubella /Measles IgM and IgG assays, Abbot Diagnostics). A urine sample was collected for virus isolation in SIRC (ATCC CL 60) and Vero (ATCC CCL 81 ) cells and incubated for $1 \mathrm{~h}$ at $37^{\circ} \mathrm{C}$. After this time, the medium was removed and replaced by L-15 medium supplemented with $2 \%$ fetal bovine serum (FBS). As the negative control of each experiment, SIRC and Vero cells were seeded in one culture flasks with culture media. The presence of infectious viral particles was controlled by the observation of cytopathic effects (CPE) by phase-contrast microscopy for seven days. Morphologically, SIRC cells consisted of elongated fibroblastic-like cells, well formed and well maintained monolayers. Viral infection manifestations in SIRC cells were a vacuolization of the cytoplasm at the cellular poles and a contraction of the cytoplasm around the altered nucleus. Finally, infected cells take on a round shape detached from the surface. Viral RNA extraction was performed from urine samples and infected culture cells were processed using PureLink Viral RNA/DNA Mini Kit (Invitrogen, USA) according to the manufacturer's recommendations. Initially, the Real Time PCR (RT-qPCR) was performed using Measles virus (MV) and Rubella virus (RV) primers, as previously described ${ }^{1,7}$. The urine sample and infected culture cells were negative for MV and RV. After this result, parvovirus B19, herpes virus 6 and Zika virus were investigated by RT-qPCR. The urine sample and the cell culture isolate were positive for Zika virus. Replication of ZIKV obtained from urine was then compared by performing kinetic measurements of virus RNA (Figure 1) by Real Time PCR for ZIKV, and negative for other viruses tested. Titrations of virus infectivity were obtained using 24-well plates with $0.2 \mathrm{~mL}$ of 10 -fold serial dilutions of virus and $100 \mathrm{uL}$ of L-15 medium supplemented with $2 \%$ FBS. The infected cells serial dilutions were tested in triplicate in the SIRC and Vero cell lines, as previously described $^{8}$. Cells were incubated at $37{ }^{\circ} \mathrm{C}$ and the $\mathrm{CPE}$ appearance observed. After 8 days, plates were discarded because the CPE was observed in $100 \%$ of the wells. The infectivity curve increased during the five days of observation. SIRC showed some CPE after $48 \mathrm{~h}$, the titers were practically the same observed in the Vero cells line.

Samples were collected from the first CPE at the dilutions of $\left(10^{-1}\right.$ to $\left.10^{-8}\right)$. Virological titers were expressed

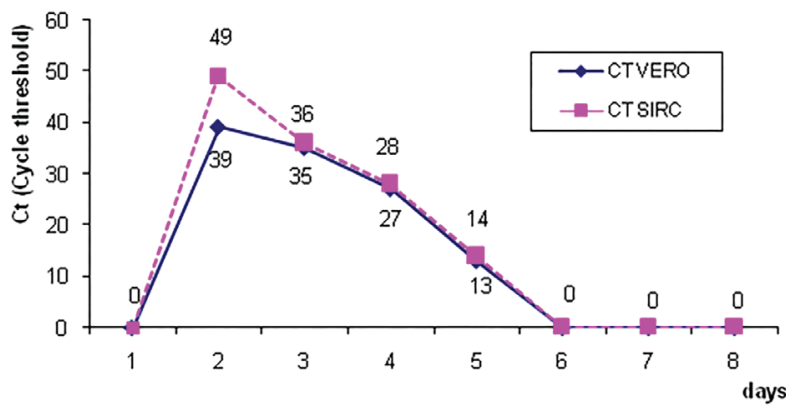

Figure 1 - Kinetic cytopathic effect of Zika virus isolated from urine in Vero and SIRC cells detected by qPCR

as the $50 \%$ tissue culture infective dose $\left(\mathrm{TCID}_{50}\right)$ according to the Reed and Muench method ${ }^{9}$. The titer was $10^{6.2}$ $\mathrm{TCID}_{50} / 0.1 \mathrm{~mL}$ in the Vero cell and $10^{6.45} \mathrm{TCID}_{50} / 0.1 \mathrm{~mL}$ in the SIRC cell. Moreover, samples were tested in the qPCR and Ct values (Threshold cycle) are shown in Figure 2.

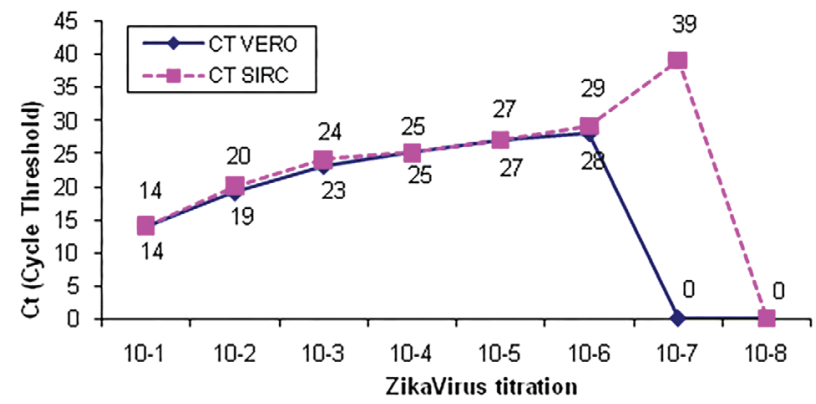

Figure 2 - Titration of Zika virus $\left(10^{-1}\right.$ to $\left.10^{-8}\right)$ isolated in Vero Cells and in the SIRC cells, showing the Ct value of each dilution used for the $\mathrm{TCID}_{50}$ calculation

For phylogenetic studies, RNA from the urine and isolated samples was amplified using primers described in the literature for the envelope region from $\mathrm{ZIKV}^{10}$. The PCR product (1550 $\mathrm{Pb}$ ) was sequenced using Big Dye Terminator v3.1 Cycle Sequencing Kit (Applied Biosystems) according to the manufacturer's protocol. ZIKV sequences derived directly from urine sample RNA and cell supernatant were deposited at GenBank accession number: MF048807 and MF048808, respectively. The sequences were aligned using Bioedt v.6 and no nucleotide/ amino acid difference were observed among the sequences (Figure 3). The Figure 4A and B show SIRC cells uninfected and infected with ZIKV respectively. Virus particle or "virion" of 50nm in diameter coming from supernatant sample of SIRC cells infected with ZIKV was observed by electron microscopy (Figure 4C). Ultrathin sections of infected SIRC cells presented virus particles with an outer envelope and inner dense core, structures similar in size and morphology of flaviviruses near endoplasmic reticulum and Golgi complex (Figure 4D). 


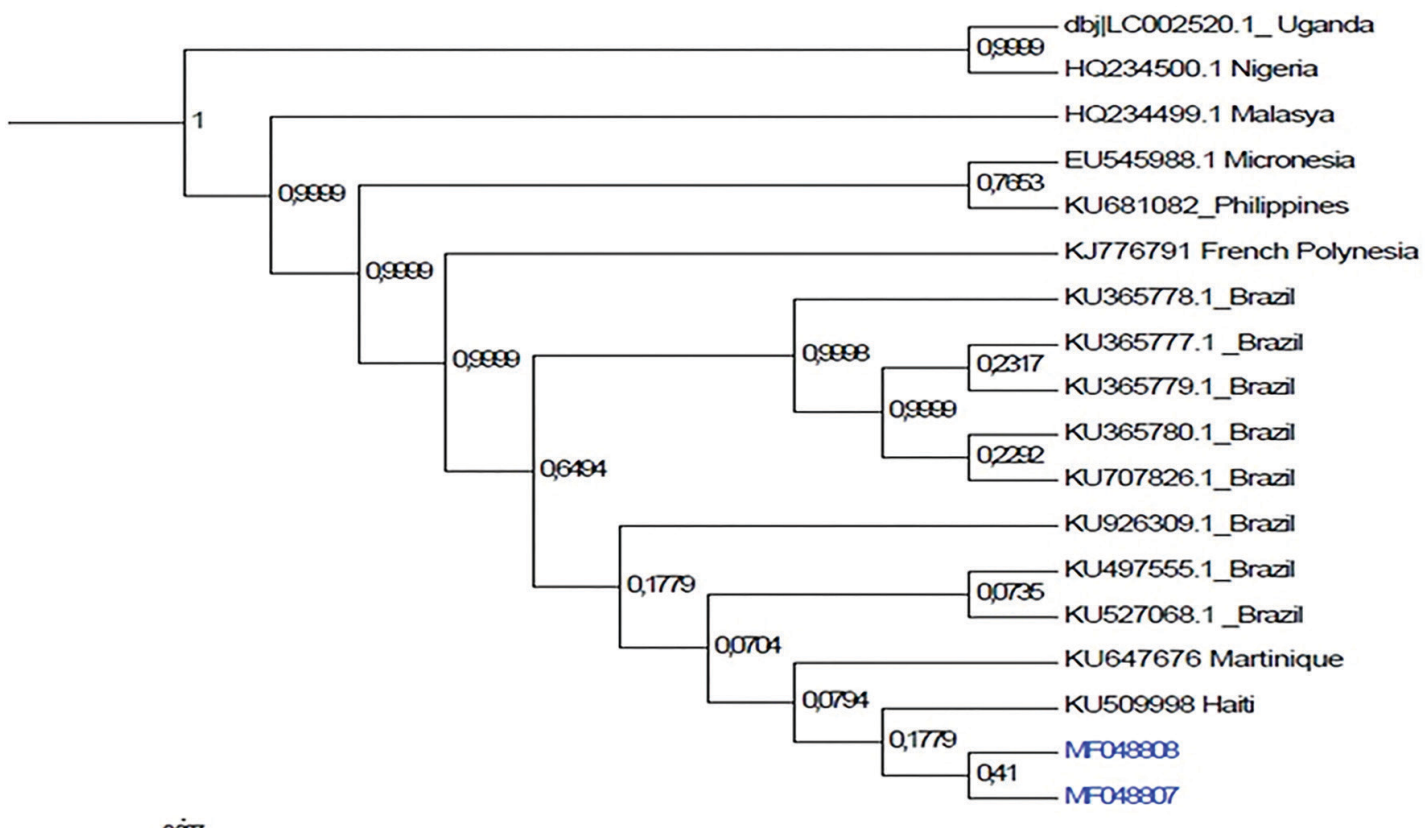

0ं்

Figure 3 - Bayesian phylogenetic tree of envelope gene sequences from Brazilian ZIKV using GTR+G+I model with the two Brazilian ZIKV strains obtained in this study MF048807 and MF048808, compared to 16 reference ZIKV sequences from GenBank. Bootstrap values are indicated at the nodes
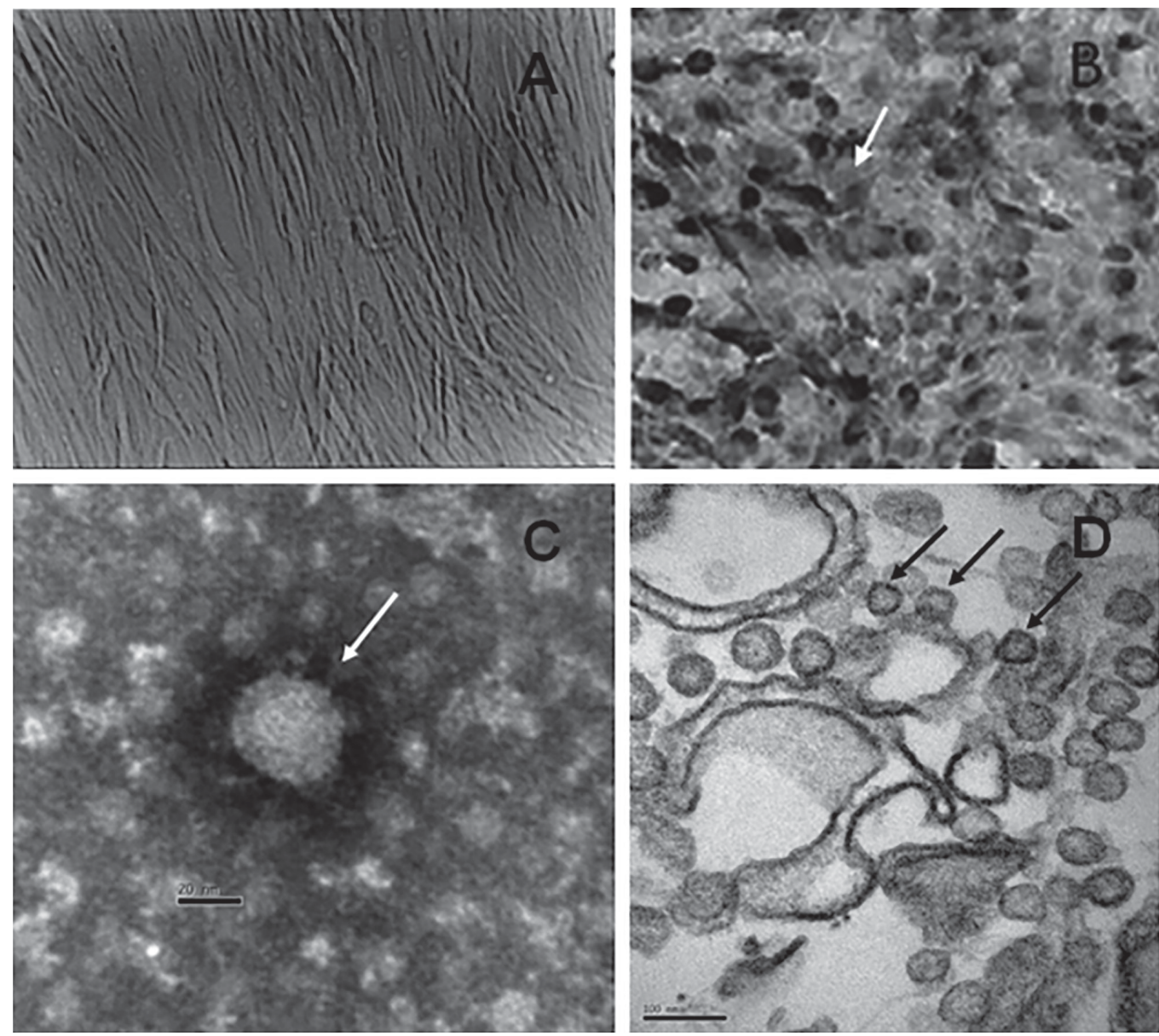

Figure 4 - A) SIRC cells uninfected; B) Cytopathic effect in SIRC cells infected with ZIKV after seven days post inoculation with a urine sample; C) Negative staining of ZIKV particle inoculated in SIRC cells observed by Transmission Electron Microscopy; D) Ultrathin section of SIRC cells showing numerous ZIKV particles near endoplasmic reticulum 


\section{DISCUSSION}

In Brazil, all cases of fever and rash meeting clinical case definitions for measles, defined as fever and maculopapular rash accompanied by $\geq 1$ of the 3 following symptoms: cough, coryza, or conjunctivitis, in any individual, regardless of age or vaccination status or rubella, defined as fever and maculopapular rash accompanied by retroauricular, occipital, or cervical lymphadenopathy in any individual, regardless of age and vaccination status, should be notified and confirmed or discarded by laboratory testing ${ }^{11,12}$. In accordance with the established procedures of the regional measles/rubella laboratory network, composed of Public Health laboratories throughout the State of Sao Paulo, laboratory evaluation of suspected cases and contacts include serologic testing, viral culture, detection of viral RNA by Real Time PCR and viral genotyping ${ }^{1,3,7}$. For this reason, the present patient was at first misdiagnosed with rubella and only later the correct diagnosis was made. Therefore, laboratory investigation is a critical prerequisite for an accurate diagnosis to determine the cause of a morbilliform rash.

In our results, we demonstrated the ZIKV isolation from a urine sample in SIRC cells culture. Infectious ZIKV particles exist in urine and saliva of patients ${ }^{13}$. The present study demonstrated that the SIRC cell line could be included in the group of cell lines in which the CPE induced by ZIKV is observed within 2-5 days of inoculation. The growth curve for the ZIKV in SIRC cells was practically the same observed in the Vero cell line. This is important because it shows that these cell lines originating from rabbit cornea can support ZIKV replication. The use of this SIRC cell line to grow ZIKV has not been previously reported. ZIKV isolation has been carried out by many groups using Vero and C6/36 cells. Therefore, we amplified and quantified viable ZIKV directly from a patient's urine sample in SIRC cells. Furthermore, we obtained a high number of ZIKV copies.

ZIKV was discovered in April 1947 during the investigation of the cause of fever in a sentinel rhesus monkey, animal number 766 that was placed in the Zika forest of Uganda as part of a yellow fever research mission sponsored by the Rockefeller Foundation ${ }^{6}$. Late in 2014, numerous cases of an exanthematous illness were reported in several regions in Brazil. Later, serologic and molecular testing implicated ZIKV in many, but not all, cases. In 2015, autochthonous transmission of ZIKV in Brazil was confirmed and, since then, ZIKV has spread extensively throughout South America, Central America, the Caribbean and Mexico. Most ZIKV infections acquired outside of the womb are asymptomatic ${ }^{6,10}$. Most infected individuals usually have mild symptoms, including rash, conjunctivitis, fever and arthralgia that typically lasts 2 to
7 days. Exposure to ZIKV during pregnancy, especially during the first trimester, is often associated with central nervous system manifestations including microcephaly, calcifications in the brain, growth restriction, and death ${ }^{11}$. Eyes are also affected including retina and optic nerve abnormalities. Nearly one third of infected women evaluated by ultrasound showed altered fetal central nervous system development ${ }^{12}$. Phylogenetic analysis results have shown that direct sequencing of clinical isolates and of cellderived supernatant (MF048807 and 048808) are similar and corroborate with previously published data that ZIKV isolates in Brazil are from the Asiatic lineage (Figure 3).

In conclusion, it was possible to isolate ZIKV from urine and culture in SIRC cells of a suspected rubella virus patient thus contributing to the differential diagnosis of acute exanthematous diseases.

\section{CONFLICT OF INTERESTS}

None declared.

\section{FUNDING}

Partially funded by FAPESP, grant N²016/14813-1.

\section{REFERENCES}

1. Figueiredo CA, Yu AL, Afonso AM, Curti SP, Oliveira MI. Molecular analysis of rubella virus in travelers suspected of measles infection in Sao Paulo, Brazil. Rev Assoc Med Bras. 2012;58:527-31.

2. Hobman T, Chantler J. Rubella virus. In: Knipe DM, Howley PM, editors-in-chief. Fields' Virology. Philadelphia: Wolters Kluwer Health: Lippincott Williams \& Wilkins; 2007. p.1069100.

3. de Moraes JC, Toscano CM, de Barros EN, Kemp B, Lievano F, Jacobson S, et al. Etiologies of rash and fever illnesses in Campinas, Brazil. J Infect Dis. 2011;204 Suppl 2:S627-36.

4. Hübschen JM, Bork SM, Brown KE, Mankertz A, Santibanez $\mathrm{S}$, Ben Mamou M, et al. Challenges of measles and rubella laboratory diagnostic in the era of elimination. Clin Microbiol Infect. 2017;23:511-5.

5. Dick GW, Kitchen SF, Haddow AJ. Zika virus. I. Isolations and serological specificity. Trans R Soc Trop Med Hyg. 1952;46:509-20.

6. Campos GS, Bandeira AC, Sardi, SI. Zika virus outbreak, Bahia, Brazil. Emerg Infect Dis. 2015;21:1885-6.

7. Oliveira MI, Afonso AM, Adelaide CF, Lemos XR, Almeida J, Frugis Yu AL, et al. Genetic diversity of measles virus resurgence of new genotype D8 in São Paulo, Brazil. Rev Inst Med Trop Sao Paulo. 2014;56:366. 
8. Figueiredo CA, Oliveira MI, Curti SP, Cruz AS, Moreira E, Afonso $\mathrm{AM}$, et al. RC-IAL cell line sensitivity of rubella virus grow. Rev Saude Publica. 2000;34:353-7.

9. Reed LJ, Muench H. A simple method of estimating fifty percent endpoints Am J Hyg. 1938;27:493-7.

10. Musso D, Rouault E, Teissier A, Lanteri MC, Zisou K, Broult $\mathrm{J}$, et al. Molecular detection of Zika virus in blood and RNA load determination during the French Polynesian outbreak. J Med Virol. 2017;89:1505-10.

11. Baud D, Gubler DJ, Schaub B, Lanteri MC, Musso D. An update on Zika virus infection. Lancet. 2017;390:2099-109.
12. Auger N, Quach C, Healy-Profitós J, Lowe AM, Arbour L. Congenital microcephaly in Quebec: baseline prevalence, risk factors and outcomes in a large cohort of neonates. Arch Dis Child Fetal Neonatal. In Press 2017.

13. Calvert AE, Biggerstaff BJ, Tanner NA, Lauterbach M, Lanciotti RS. Rapid colorimetric detection of Zika virus from serum and urine specimens by reverse transcription loopmediated isothermal amplification (RT-LAMP). PLoS One. 2017;12:e185340. 